\title{
Global Heritage Stone Resource: An Update
}

\section{Preface}

\author{
Guest Editors \\ Dolores Pereira $^{1}$, S. Kramar ${ }^{2}$ and Barry J.Cooper ${ }^{3}$ \\ ${ }^{1}$ Department of Geology, Plaza de la Merced s/n, University of Salamanca, 37008 Salamanca, Spain. \\ E-mail:mdp@usal.es \\ ${ }^{2}$ Slovenian National Building and Civil Engineering Institute, Dimiceva 12, 1000 Ljubljana, Slovenia. \\ E-mail: sabina.kramar@zag.si \\ ${ }^{3}$ Barbara Hardy Institute, School of Natural \& Built Environments, University of South Australia, \\ Mawson Lakes SA 5095 Australia. E-mail: barry.cooper@unisa.edu.au
}

This issue of Episodes is a special issue dedicated to heritage stone; those stones that have special significance in human culture. Examples include some very important natural stones that have been either neglected because they are no longer extracted, or rock types that have great significance in commercial terms, but where knowledge on their international heritage is not well documented. The Heritage Stone Task Group (an IUGS Task Group) has the role to establish a new formal geological designation: the "Global Heritage Stone Resource" where a natural stone has special international significance.

The objective of this collection of papers is neither to emphasize the specific geological characteristics of the rocks with heritage attributes, or to recommend (or ban) their use for new construction. Our aim is to spread awareness of architectonic heritage and the natural stones that have been utilised. Accompanying this enhanced appreciation is the need to preserve the historical quarries that once provided the source for such stone. These quarries are linked to regional culture and local society, yet so often today, as a consequence of modern transportation, improved infrastructure, or even globalization related to imports and exports of exotic dimension stones, they lie idle. Nevertheless, due to the specific technical and aesthetical characteristics of such heritage stones, these historical quarries should be preserved and used, sometimes with restrictions, in case of the restoration of monuments and historical buildings in order to avoid the disastrous actions that have been observed in some restorations even in World Heritage Cities.

This special issue comprises papers that have been sourced from presentations to a session on Heritage Stone that was held as part of the General Assembly of European Geosciences Union, held in Vienna in April 2014 , and supplemented with contributions from other authors who are enthusiastic about this concept. This issue also complements a newly issued Special Publication of Geological Society of London entitled "Global Heritage Stone: Towards international recognition of building and ornamental stones". It is our hope to provide further contributions on this subject in future issues of Episodes.

The Editors of this issue greatly appreciate the work of the authors and reviewers as well as IUGS support for the ongoing work of the Heritage Stone Task Group. 